\title{
Resection of complex occipital arteriovenous malformation with giant varix: demonstration of microsurgical technique
}

\author{
Pinar Eser Ocak, MD, Cem Dinc, MD, Ulaş Cikla, MD, and Mustafa K. Başkaya, MD \\ Department of Neurological Surgery, University of Wisconsin Medical School, Madison, Wisconsin \\ The complexity of arteriovenous malformations (AVMs) does not necessarily preclude surgical resection. In this video \\ the authors present a 72-year-old male who was known to have an occipital AVM with a large draining varix for the previ- \\ ous 10 years. The patient had progressively worsening visual and cognitive deficits over several years. Total surgical \\ resection was achieved following single stage preoperative embolization. Although resection of the AVMs is challenging, \\ even in experienced hands, it offers a cure and may improve patient clinical outcome.
}

The video can be found here: https://youtu.be/YI1AwGJJdvo.

KEYWORDS AVM; arteriovenous malformation; microsurgery; occipital lobe; varix 